\title{
Scaling the Rural: Reflections on Rural Cultural Studies
}

\section{Andrew Gorman-Murray, Kate Darian-Smith and Chris Gibson}

How can cultural analysis be brought to bear on the rural? This central question for rural cultural studies prompts our exploration of how the rural has been delineated and interpreted in the developed West, as a departure for thinking about new intellectual approaches to rurality that span spaces, times and academic disciplines. In this paper we adopt a broad schema, discussing insights from rural studies, cultural geography and history. As Michael Woods (Rural Geography) has handily pointed out, 'rural' is

one of those curious words which everyone thinks they know what it means, but which is actually very difficult to define precisely. Attempts by academics to define and delimit rural areas and rural societies have always run into problems, sometimes because the distinctions they have drawn have been rather arbitrary, sometimes because they have over-emphasised the differences between city and country, and sometimes because they have under-emphasised the diversity of the countryside. (15, emphasis added)

The complexity and variations of rural environments, economies and populations in Australia is illuminated in our discussion of how the rural may be conceived of through five different scales: the global, the national, the state, the regional or local, and the bodily (or at least at the level of individuals). We extend existing debates about defining 'the rural' and 'rurality', seeking a more nuanced multi-scalar reading of the meaning of the rural within contemporary Australian culture and society. The spatially specific aspect of this broad sketch is particularly germane to recent concerns in the discipline of geography about the social construction of scale (Marston 'The Social', 'A Long Way'), and it responds to calls to pay greater attention to the role of scale in rural studies (Bell; Little and Austin). It also emerges from claims that the rural has been neglected in recent historical discourse (Darian-Smith) and that as a consequence much academic commentary on contemporary rural issues in Australia is 'strangely disconnected from an understanding of the longer course of Australian rural history' (Davison and Brodie xi). We hope both to draw upon and move beyond our specific disciplinary backgrounds in geography and history to engage with a new framework for thinking about rural cultures in Australia. 


\section{Cultural approaches to defining 'the rural': historical and geographical perspectives}

In the 1990s rural studies was reinvigorated by the cultural turn and the recognition of the importance of culture within rurality and its definitions (Cloke 'Country'; Rye). Such cultural approaches challenged the definition of the rural as an objectively measurable material or physical space demarcated through quantifiable demographic or social differences, such as population density or distinct economic activities such as agriculture, mining or forestry. As a consequence, scholarly attention turned to representations of the rural, conceived 'as [a] subjective and socially constructed phenomena, located in people's minds' (Rye 409; Cloke 'Country'; Halfacree; Mormont; Phillips). As Mormont (36) puts it, 'rurality is not a thing or a territorial unit, but derives from the social production of meaning'. The rural, then, is a symbolic lens for certain moral and cultural values which vary across time and space. Popular representations of the rural in the spheres of public policy, everyday cultural life and social norms derive from representational processes, as acknowledged by recent work in geography (Little and Austin; Phillips et al; Rye; Short; Vanderbeck and Dunkley).

The variable meanings of the rural are, of course, embedded in wider narratives that locate people as members of spatially and historically diverse communities at local, national and global levels. Since the European occupation of Australia and the dispossession of Indigenous peoples, the impulse to own land and to render it productive through agricultural, pastoral and mining activities has been central to the development of colonial and national economies, social and political institutions and the dynamics of Australian culture (Waterhouse). The mythology of 'the bush' and the sometimes competing values of itinerant rural workers and the yeoman pioneer, for example, were not only influential in the literary and visual expressions of late nineteenth-century nationalism, but have remained central to evolving definitions of Australian identity and values, and are foundational to Australian nationalist historiography (Hirst; Ward; Waterhouse $166-193)$.

At the time of Federation, for example, the Australian economy was dominated by the primary sector, and almost half the Australian population lived in rural towns with a population less than 3000 . But the glamorous and gritty urbanism of the capital cities (think of 'Marvellous Melbourne' and its darker and morally deficient underside), their suburban respectability, and their growing manufacturing base, were already well established in the iconography of Australian public culture (see, for instance, Davison 'The Rise'; Forster). Thus, by the late nineteenth century, even as much of the marginally arable land within the continent was still being cleared, there was already a tendency to nostalgia for the heroic feats of the pioneering days, as well as a widespread 
acknowledgement that life on the land was potentially one of struggle. By the 1930s, as Depression and drought drove many farming families off the land, the qualities associated with rural populations - especially a capacity for hard work - were increasingly seen to be embodied in those living in country towns, which became symbolic of the stability of 'traditional' agrarian communities (Brodie).

This is not to suggest that the history of agricultural and other primary production in Australia was lacking in innovation. As Heather Goodall has put it, the rural in Australia was 'born modern'. Agricultural, pastoral and mining industries in Australia were, from the early colonial period, associated with experimentation, invention and the scientific taming of a new environment so that it was rendered productive in a European sense. The introduction of the merino sheep, the invention of the stump-jump plough, and the extraordinary discourses of progress that characterised the Murray River towns of Mildura and Renmark in the late nineteenth century (as irrigation made the deserts bloom) are all evidence of the deliberate transformation of the Australian interior into modern cultural landscapes or 'second natures', put to productive use (see Anderson).

The rapid spread of mechanisation in the mid-twentieth century, and the take-up of new farming technologies after the Second World War ensured that primary production, including minerals exploration, boomed in the 1950s and 1960s. Nevertheless, since the 1970s, the primary economy has been shaken by the deregulation of agricultural industries, environmental and climatic impacts, changing consumer demands and global markets. The decades since have seen a decline (with many regional variations) in the non-metropolitan workforce and in the provision of rural infrastructure. With agriculture now accounting for less than 5 per cent of Australia's economic production, over the past decade rural Australia has been widely represented in the media and in government policy as being 'in crisis' - as a 'land of discontent' and a victim of 'global misfortune' in desperate need of 'renewal' (Darian-Smith; Gray and Lawrence; Pritchard and McManus).

Such popular contemporary definitions of the rural in Australia as 'trouble', or at best 'troubled', simultaneously construct it in relation (and often in opposition) to the urban. Of course, this is not new: there is a long tradition of 'objective' definitions of the rural which compare rural and urban spaces, assigning attributes like low population density and agrarian economic activity to the former and high density population and mixed economic activity to the latter. Raymond Williams' classic study of the city and country focussed on the continuing relationships of these two sites in an industrialised Europe (although we note that the city/country terminology also differs in certain symbolic ways from that of urban/rural). The ideal of 'country life', transplanted from Europe 
to Australia, has had a long hold on Australian culture ever since colonisation, but always in some tension with metropolitan living (Davison and Brodie). However, the shift in the material realities of rural spaces means that the historical contours of the urban/rural comparison have now taken on different forms. Indeed, the quantification of rural difference has been challenged by demographic movement-including the internal migration of urban-dwellers to sea-change and tree-change destinations - and in some rural areas by the move of economic activities away from primary production to service industries, including tourism and cultural industries. In contemporary Australia the rural has become a symbolic marker of social, cultural and moral values that are defined more by perceived limitations than any sense of agricultural or indeed social progressiveness - it is a spatial imaginary increasingly detached from agrarian spaces per se (Bell; Cloke 'Country'; Phillips et al).

This disruption of the cultural construction of the rural can also unsettle the conventional ways rural landscapes and livelihoods have been imagined. As Woods argues, '[a]griculture is one of the most potent and enduring emblems of rurality. For centuries, agriculture was in most rural regions not only the overwhelmingly dominant source of employment, but also the driving force of the rural economy and a pervasive influence in the organization of rural society and culture' (Rural Geography 42). But the link between agrarianism and rurality is not essential (and has been unproblematically essentialised). In Australia, rural economies have not been limited to agricultural pursuits but have encompassed other primary industries such as forestry, fishing and, most importantly with reference to the current resources surge, the mining industries. These sectors have not been discrete, but have often been connected through patterns of investment, ownership and employment (see Woods, Rural Geography). Given the recent post-productivist turn, to this mix we can add associations of rurality with tourism and leisure activities, producing further fractures in rural imagery between what we can think of as agrarian 'farmscapes', untamed 'wildscapes' and sporting 'adventurescapes' (Bell, 'Variations'). As a result, the cultural construction of the Australian rural must now accommodate a fluid and diverse range of landscapes, livelihoods and industries.

Studies of rural representations are additionally crosscut by variations in the contours of urban/rural difference in national contexts. Gill Valentine, for instance, describes how 'idyllic' notions of the rural differ between the USA, the UK, New Zealand and Australia. Within these national locations, the rural can encompass quaint villages, fields of broad-acre farms, lushly forested wilderness, and frontier territory. The national context is critical to the social and cultural definition of rurality (Allen; Little and Austin), and in Australia the very distinctiveness of the environment and climate, among other factors, influences how we imagine it. At the same time, the national meanings associated with rurality shift with scale; the English rural idyll is represented differently 
on its national and local scales (Cloke and Milbourne; Little and Austin), while both local and national understandings feed into the circulation of global projections of rurality (Bell). Within these jostling spatial scales, there are also distinct historical shifts which adjust the reception of constructions of the rural. For instance the powerful media representations of drought (cracked red earth, starving sheep in the paddock) and the demographic decline of country towns (boarded up shopfronts, and absence of services) that have been dominant in metropolitan media markets from the mid 1990s contrast markedly with images aimed at British migrants in the 1950s and 1960s that depicted Australia through the abundance of its agricultural production and associated opportunities (Darian-Smith, 'Up the Country').

In examining the spatial and temporal scales of definitions of Australian rurality in the remainder of this paper, we turn to some examples drawn from the complex range of tourist imagery about Australia and its non-metropolitan features. Tourist campaigns are particularly apt for this discussion because in themselves they rhetorically deploy (and indeed shape) a multi-scalar approach directed at variously imagined, and highly differentiated, audiences or market sectors - which range from international travellers to interstate tourists to those individuals seeking weekend rejuvenation and encompass family holidays, backpacker experiences and retirees with caravans. This provides an accessible entry to thinking through the interwoven spatial and temporal scales that evoke Australian rurality.

\section{Global, national and state scales}

In recent years, scholarly attention has been directed towards what David Bell (154) calls the 'transnational rural' or the way the rural can be imagined globally (see also Woods, 'Engaging' and McCarthy on 'global countryside'). Bell is interested in how certain images of the rural are circulated internationally and in this process become normalised. But how might Australia, with its current urbanisation of 86 percent of the population, be imagined within the framework of the transnational rural?

The persistence of the global view of Australia stems from its history as a white settler colony within the British Empire. From the time of European settlement, Australia has often been understood by its colonial population and within the wider imperial sphere, including North America, as a sparsely settled, wild and 'untamed' continent, as 'frontier' territory - land farthest from white civilisation and metropolitan domesticity. The Australian frontier was, as in other colonial societies, the place where white settlers and Indigenous peoples met, often in violent clashes. Much historical inquiry in recent decades has been directed at exploring the gendered and racial dimensions of these interactions, and what Henry Reynolds has famously called 'the other side of the frontier' (Reynolds). These historical legacies were central to the overturning of the legal dictum of 
terra nullius in 1992, and the historicisation of the colonisation of rural (or at least non-urban) Australia dominated the history wars of the Howard era (Macintyre and Clark). The rural imagery associated with the Australian landscape, from the 'bush' to the 'outback' desert, is historically grounded, although the association of the outback with Aboriginal Australia can also situate this landscape as simultaneously pre-historical and post-colonial.

Global imagery surrounding the rural in Australia is also economically grounded, linking rural industries to Australia's international profile as a primary producer. From the colonial period, sheep and wool were the basis of the economy, and by the 1850s the colony of Victoria was the richest gold-producer in the world. Australia was 'born modern' in the sense that its economic development was driven by newly emerging international markets for the export of primary produce. The symbolic values associated with agriculture differed wildly from those of mining, but both drew on transnational histories and experiences. The nineteenth-century goldfields, for instance, were associated with social instability and transient populations, and sustained part of a global diaspora of Chinese migrant labour. In this aspect, there is continuity, although also considerable differences, with the fly-in/fly-out patterns of employment organisation in Australia's contemporary mining sites. Again, the images and practices associated with contemporary Australian mining are not conceived within an exclusively Australian framework, but draw on discourses associated with the global mining industries, in particular in terms of their environmental impact, forms of unionisation, management and operating standards that connect mining operations at the transnational level. While global tourism is also now central to Australia's economy, the images it constructs of Australia as an unspoilt wilderness represent significant continuity with these older transnational rural stereotypes. They draw on the persistent notion of Australia as frontier territory, with a focus on its landscape and natural attributes. Australia is 'sold' to the world through images of the outback; of sand, sun and surf; and through its 'exotic' native wildlife (Waitt).

Bell's idea of the transnational rural is provocative precisely because, in the West, the rural is often equated with regional hinterlands within the nation-state. But cultural constructions of idyllic ruralities circulate across nations and geographical regions, so that there are certain rural symbolisms which transcend these scales. In Australia, country music and the recent lifestyle trend for idyllic rural retreats - not to mention agricultural technology and ideas about land use management - have evolved from cultural formations originating in Europe, North America and parts of Asia. This global transmission of ideas, culture and technologies to Australia has resulted in their reinvention and innovative applications in accordance with localised situations (Woods, 'Engaging'), and in some instances their global re-circulation. 
For instance, recent work by historian James Boyce on Van Diemen's Land examines how early free settlers mimicked an old world sensibility in the creation of Georgian manors surrounded by estates. Max Staples also discusses the way the historical and contemporary social construction of the Tasmanian landscape has positioned the island as a 'Little England', with England imagined as the archetypal 'rural idyll'. While Australia may be seen as the last rural (or wilderness) retreat from an industrialised Europe, and indeed is marketed as such in international tourist promotional material, at the same time an imaginary rural English landscape is cast in a domestic or national sense as the last rural retreat from the stresses of contemporary Australian life. Such an interplay between European notions of rural landscapes and pursuits and their realisation in Australia is also evident in the construction and marketing of Hepburn Shire, Victoria, as 'spa country', conjuring up images transplanted from the 'spa resorts' of nineteenth century England (Gorman-Murray, Waitt and Gibson, 'Chilling Out', 'A Queer').

The international distribution of country music and western films as particular cultural products originating in the US, have also been influential in the way the rural or the country has been imagined in different localities across the globe. Studies of rural festivals in Australia, such as the Tamworth Country Music Festival and the Parkes Elvis Revival Festival (Brennan-Horley, Connell and Gibson; Gibson and Davidson) show how these are dominated by US-imported visual (and aural) imagery associated with what we might see as 'global' country culture. And to take a final example, we might also think of the transposition of 'Bali-style' guest houses to 'idyllic' rural locations such as Byron Bay, or other Asian-inspired tourist retreats in tropical Queensland or places like Broome. Here the recreation of an Asian rurality, whether as a 'generic' or more specific cultural evocation (and at times a combination of the two) can also be linked historically to patterns of migration and the fusion of diverse cultures.

Alongside these global evocations, the rural is often positioned on the national scale as a symbolic site for authentic national values, a 'receptacle for ... shoring up what it means to be English, or Dutch, or whatever' (Bell 151). This has certainly been the convention in Australia, illustrated in the way that the values of the bush, for instance, came to infuse the representation of another central national icon, the Gallipoli digger. While contemporary Australia is becoming more cautious about presenting rural images as a distinctive marker of nation, nevertheless in the 'story' of Australia performed at the 2000 Sydney Olympic Games (and viewed by an international audience of 3.5 billion people) the mounted (male) bush worker was presented as 'a quintessential idea' of national identity (Elder 34), supported by representations of the forces of land and nature, Indigenous Australians, and migration and settlement as contributors to 'being Australian'. 
The national scale similarly balances cultural and economic considerations. In the decades after Federation until its dismantlement in the neo-liberal economic reforms of the 1980s, state protectionism encompassed support for the country and its interests. This was underpinned not only by the reliance on the primary economy, but on a political culture that stressed the significance of rural values and the commitment of the nation to populate the continent. This view was exemplified by the ideology of the Country Party, defined by Aitkin as 'country-mindedness', a belief that rural communities should be compensated for their disproportionate economic and cultural contribution to the nation, and that regional equality was a 'right'. As Judith Brett puts it: 'At one time the problems of the country were the problems for the country as a whole' (14). In the 1990s, as Pauline Hanson's One Nation Party rose and fell, the newer, but deep-seated politics of alienation and discontent among some (but not all) rural communities illustrated sharply how 'the rural' could not be ignored within national conservative politics or indeed across the political spectrum.

At the same time, shifting definitions of rurality are critical to the political and legislative function of the Australian states and territories, with some positioned as 'more rural' within the nation itself. Bureaucratic definitions at the scale of the state, of course, have shifted over time and according to political expediency, and tend to collapse the definitions of state and regional: under the Howard government, the terms 'the bush', 'the regions' and 'rural and regional' were increasingly used in political vernacular to mean the same thing. Nevertheless, official meanings attributed to these categories narrowed considerably in accordance with specific policy frameworks.

Official demographic statistics produced by the Australian Bureau of Statistics, for example, define five types of census collection districts across Australia according to accessibility to and remoteness from major urban centres: Major Cities of Australia, Inner Regional Australia, Outer Regional Australia, Remote Australia, and Very Remote Australia (ABS, 2003). This has implications for how urban/rural difference across Australia is 'operationalised' in policy frameworks. According to these definitions, entire states and territories are non-metropolitan. The Northern Territory, for instance, is entirely classified as non-metropolitan, ranging from Outer Regional (Darwin) to Very Remote. Tasmania ranges from Inner Regional (Hobart) to Remote. Most of the Northern Territory, South Australia and Western Australia are classified as Very Remote. Conversely, only a fraction of New South Wales is Very Remote, and none of Victoria falls into that category. These bureaucratic and demographic definitions of the rural and regional do not always match up to broader cultural understandings of what the rural may be, or to the self-positioning of particular towns or non-metropolitan regions. While it might be relatively unproblematic to view the entire Northern Territory as non-metropolitan, it is more difficult in a commonsense way to equate it with rurality. 
Likewise, tourism images of Australia aimed at domestic and international audiences imagine the internal variables of rurality in different ways, with some states and territories being represented as more rural and some as more metropolitan. (Australian state borders were, of course, artificially placed across the nation/continent, and as a consequence border regions offer particularly clear illustrations of the construction of rurality in relation to legislative and social contexts.) The features of the rural invoked in tourist images range widely: the Northern Territory and Western Australia are positioned as 'outback', Tasmania as 'wilderness', Queensland as 'tropical paradise'. Meanwhile, New South Wales and Victoria (as the industrialised, economically diverse states) are often imagined through their large state capitals, Sydney and Melbourne. South Australia appears as the state 'in-between', with a little bit of everything (from the city of Adelaide to the gateway to the outback) but seemingly distinguished by nothing in particular; the ACT as bush capital of international significance. Where rural images of New South Wales and Victoria are seen, they are often the 'cultivated rusticity' of a more Euro-American idyllic variety-vineyards, wine regions, pastoral settings. Perhaps it is no surprise that recent Tourism Victoria advertisements are set in vineyards, using the tune 'Run Rabbit Run' to allude to a non-native animal (the rabbit) as an icon of Victorian rurality.

\section{Regional/local and individual scales}

Just as the Australian continent is politically and legislatively divided by state boundaries, so is it internally defined by socially affective regions, localities and communities. Within these (and sometimes across them) there may be regional articulations of rurality. Regions are shaped by their colonial histories, their topography and environment, and their economic, social and political compositions, as much as by their local government designations, which have, of course, altered over time. Such mappings of the continent are transposed over the boundaries of traditional Indigenous territories, which are perhaps best known through David Horton's map of Aboriginal Australia (1994), supplemented by recognised and ongoing Native Title claims. The regional scale of how we might understand settler and Indigenous identities and experiences, and for our purposes the concept of the rural, has been under-emphasised in Australia. But it is in regional histories, more theoretically informed and expansive since the 1980s, that identification with particular places and landscapes and a sense of regional belonging have been expressed forcefully (French). And it is in the vigorous tradition of local histories, many concerned with non-metropolitan localities, that the connections between places and their communities continue to be narrated (Davison, 'Local History').

Since the nineteenth century, these regional and local identifications have often been incorporated in domestic tourism campaigns. As contemporary advertisements such as Tourism Victoria's 'You'll love every piece of Victoria' 
campaign suggest, the different regions within states are also culturally constructed in ways that may differ from the national or international representations of the rural, or which may hybridise localised elements with 'travelling' representations of the rural. In contrast to allusions to taming the land or the frontier nation, the region in Australia is often represented in terms similar to the Euro-American rural idyll. We currently see advertisements and images for the 'wine regions' of the Hunter Valley, Barossa Valley, Margaret River or Stanthorpe, or 'dairy regions' like the Eurobodalla and the far south coast of New South Wales or Victoria's Gippsland. It is here, then, that what Bell calls the gastro-idyll or pastoral idyll comes into play: the rural as a gentrified and domesticated landscape which yields specialised and desirable cuisine, which might include 'bush tucker' and indigenous flora and fauna. Such regions are often associated with tourism of a more cosmopolitan variety, with city-dwellers retreating to the country, 'chilling out', and reviving body, mind and soul through wine tastings, farm stays and spa treatments. They are also associated with the 'new economies' of metropolitan values transposed to selected rural areas, and not surprisingly they are generally easily accessed (by car) from Australia's capital cities.

The discourse of rurality at this localised scale of gentrified tourism can be seen to be gendered in more feminised terms than the rugged masculinity associated, both historically and culturally, with pioneering, farming and rural labour. Where the Euro-American style rural idyll comes into play, so too do its attributes, with rural communities often imagined as safe, secure, tight-knit and family-centred (Little and Austin; Valentine). These virtues have a long trajectory of being seen as upheld by the community work of rural women - in this instance as nurturers, carers, wives, mothers and community volunteers (Allen; Little and Austin).

The gendered embodiment of rurality is geographically, historically and culturally complex, and in Australia the demographic realities of rural settlement, where white women were (and in many areas remain) under-represented, have resulted in concerted government attempts from the 1920s to improve the 'attractiveness' of rural life through the provision of such services as maternal and child health services and the provision of domestic technology. A study of young women's participation in post-war 'Miss Showgirl' competitions held at annual agricultural shows illustrates how these women were represented as embodying the values of rural femininity on scales that were highly localised while simultaneously conceptualising femininity in national terms (Darian-Smith and Wills).

This introduces us to the final scale of rurality - that of the body itself. Jo Little, for instance, has urged more work on understanding the construction of rural masculinities and femininities at the scale of the body, and argues that embodied 
performances are bound up with the rural environment and community. We have seen how the rural can be embodied through both women and men on different scales, producing stereotypes of the ideal country man or woman. The national scale evokes the historical frontier or bush mythology, which in turn idealises the hardened male body as the vector of exploration, conquest and productivity (Cloke, 'Masculinity'). Meanwhile, the regional scale of the rural idyll and tight-knit community and family values evokes the feminine as the embodiment of selflessness and succour (Allen; Little and Austin). But these images, as stereotypes, also draw attention to what is missing from Australian rural imaginaries. Rural bodies are predominantly white and heterosexual, for instance (Gibson and Davidson). They tend towards individualism or an imagined rural 'classlessness' (or egalitarianism) as the embodiment of honest labour. The ethnic diversity of rural towns has been historically obscured, although this may be now selectively celebrated as a marker of the history and the associated economies of particular towns or regions (as in Griffith or Broome), and linked to heritage, festivals and cultural tourism.

Of course, there are other images of rural bodies as well. In Northern Territory and outback Queensland tourism, representations of Indigenous bodies are common, and are always placed in distinctly non-urban settings. It is as if the Indigenous body itself is an exemplar of the 'untouched' natural environment or 'wilderness' of Australia. And just as the rural idyll may be a store for old-fashioned values, the association of the Indigenous body with the landscape also evokes westernised hierarchies of race and culture - these bodies are seen to be at one with a landscape imagined as 'timeless' and 'ancient' (Dunbar-Hall and Gibson; Lane and Waitt). Indigenous Australians are too rarely associated with the promotion of urban settings despite the fact that the majority of the Indigenous population live in major towns or cities. And of course, images of remote and rural Aboriginal communities as places of cultural despair, populated by people who need 'rescuing' through government intervention (Lawrence and Gibson), have been prominent in the media. Such representations gesture towards the continuity of a 'frontier' outside the capital cities. This is in stark contrast, in a cultural, racial, geographical and imaginary sense, to the notion of the packaged rural idyll of domesticated weekend tourism, where the restorative qualities of the rural transform and rejuvenate urban-dwellers.

\section{Conclusion}

Here, then, are five interconnected scales of the rural in the Australian context. They are not meant to be definitive, but rather to suggest in a synthetic way how rural imaginaries are put to use and perform cultural work in contemporary Australian society. These discussions prompt greater consideration of the role of scale in how the rural is evoked and experienced, and how that further 
multiplies the way the rural can be defined in forms that may be bureaucratic as well as symbolic or representative.

From our perspective, there are (at least) two further queries left unaddressed here, but which in some ways are taken up by subsequent papers in this collection of essays. The first concerns the utility of the lingering rural-urban binary. At the very least, because the rural is often imagined in opposition to the urban or metropolitan, our multi-scalar discussion calls for a further deconstruction of this binary. If the rural can be constructed simultaneously across multiple scales, from the body to the globe, where then is the urban? How can the urban itself be imagined in any fixed sense? And if the Australian nation is imagined in rural terms in a global context, against what urban are rural regions within Australia imagined?

Our second query is whether cultural analysis of 'the rural' can take up the challenge, one most vigorously articulated in British geographical circles recently, to move beyond deconstruction and reliance on purely representational worlds so as to 're-materialise' rural studies while remaining sensitive to the operation and power of cultural discourse. How do the people who inhabit 'rural Australia' (however defined) make sense of the cacophony of multi-scaled, somewhat contradictory rural imagery sketched above? To what extent are rural idylls, frontier images and pastoral discourses commensurate with, or a challenge to, the everyday lives of contemporary rural residents? Or more modestly, what attracts (or repels) people from all backgrounds to rural culture and places? Much is said about 'living on the land', but what might this really mean for how humans, climate and landscape interact in rural cultures? It is abundantly clear that 'the rural' has discursive power, and hence its deployment by governments seeking to achieve certain kinds of policy ends. But there is more at work and at stake in the cultural construction of rurality in Australia than mere symbolism. Rural people and all varieties of non-human entities and technologies (from new crop varieties to national parks, from tourist brochures to farm machinery and mobile phones) are intricately embedded in the interconnected and historically-grounded production of rural places in Australia.

Andrew Gorman-Murray is a Research Fellow in Human Geography at the University of Wollongong, working across social, cultural and political geography. His research ranges over geographies of sexuality and gender, geographies of housing and home, rural and (sub)urban geographies, the politics of belonging, cultures of nature, migration and population dynamics, and cultural heritage and tourism.

Kate Darian-Smith is Professor of Australian Studies and History in the School of Historical Studies, University of Melbourne. She has published widely in Australian cultural history, with work on rural topics including studies of agricultural shows, community amenities in country towns, frontier histories and rural heritage. She 
convenes, with Chris Gibson, the Cultural Histories and Geographies node of the $A R C$ Cultural Research Network, and its Rural Cultural Research program.

Chris Gibson is Associate Professor in Human Geography at the University of Wollongong. He is the co-author (with John Connell) of Sound Tracks: Popular Music, Identity and Place (Routledge 2003) and the forthcoming Music Festivals and Rural Development in Australia (Ashgate, 2009).

\section{Works Cited}

Aitkin, Don. "'Countrymindedness": The Spread of an Idea.' Australian Cultural History 4 (1985): 34-41.

Allen, Kerry-Elizabeth. 'The Social Space(s) of Rural Women.' Rural Society 12.1 (2002): 27-44.

Anderson, Kay. 'White Natures: Sydney's Royal Agricultural Show in Post-Humanist Perspective.' Transactions of the Institute of British Geographers 28 (2003): 422-441.

Australian Bureau of Statistics. ASGC Remoteness Classification: Purpose and Use. Canberra: Commonwealth of Australia. Census Paper Number 03/01, 2003.

Bell, David. 'Variations on the Rural Idyll.' Handbook of Rural Studies. Eds Paul Cloke, Terry Marsden, and Patrick Mooney. London: Sage, 2006. 149-160.

Boyce, James. Van Diemen's Land. Melbourne: Black Ink, 2008.

Brennan-Horley, Chris, John Connell and Chris Gibson. 'The Parkes Elvis Revival Festival: Economic Development and Contested Place Identities in Rural Australia.' Geographical Research 45.1 (2007): 71-84.

Brett, Judith. 'The Country, The City and The State in the Australian Settlement.' Australian Journal of Political Science 42.1 (2007): 1-17.

Brodie, Marc. 'The Politics of Rural Nostalgia Between the Wars.' Struggle Country: The Rural Ideal in Twentieth Century Australia. Eds Graeme Davison and Marc Brodie. Melbourne: Monash U e-Press, 2005. 09.1-09.13.

Cloke, Paul. 'Country Backwater to Virtual Village? Rural Studies and 'The Cultural Turn'.' Journal of Rural Studies 13.4 (1997): 367-375.

_- 'Masculinity and Rurality.' Spaces of Masculinities. Eds B. Van Hoven and K. Horschelmann. London: Routledge, 2005. 45-62.

— , and Paul Milbourne. 'Deprivation and Lifestyles in Rural Wales.' Journal of Rural Studies 8.4 (1992): 359-371. 
Darian-Smith, Kate. 'Up the Country: Histories and Communities.' Australian Historical Studies 33.118 (2002): 90-99.

— , and Sara Wills. 'From Queen of Agriculture to Miss Showgirl: Embodying Rurality in Twentieth-Century Australia.' Journal of Australian Studies 71 (2001): 17-32.

Davison, Graeme. 'Country Life: The Rise and Decline of an Australian Ideal.' Struggle Country: The Rural Ideal in Twentieth Century Australia. Eds Graeme Davison and Marc. Brodie. Melbourne: Monash U e-Press, 2005. 01.1-01.15.

—. 'Local History' The Oxford Companion to Australian History. Eds Graeme Davison, John Hirst, and Stuart Macintyre. Melbourne: Oxford UP, 1998. 397-8.

- The Rise and Fall of Marvellous Melbourne. Melbourne, Melbourne UP, 1978.

— and Marc Brodie. 'Introduction.' Struggle Country: The Rural Ideal in Twentieth Century Australia. Eds Graeme Davison and Marc Brodie. Melbourne: Monash University e-Press, 2005. ix-xvi.

Dunbar-Hall, Peter and Chris Gibson. Deadly Sounds, Deadly Places: Contemporary Aboriginal Music in Australia. Sydney: UNSW Press, 2004.

Elder, Catriona. Being Australia: Narratives of National Identity. Sydney: Allen \& Unwin, 2007.

Forster, Clive. Australian Cities: Continuity and Change. Third ed. South Melbourne: Oxford UP, 2004.

French, Maurice. 'Regional History.' The Oxford Companion to Australian History. Eds Graeme Davison, John Hirst, and Stuart Macintyre. Melbourne: Oxford UP, 1998. 548-9.

Gray, Ian and Geoffrey Lawrence. A Future for Regional Australia: Escaping Regional Misfortune. Melbourne: Cambridge UP, 2001.

Gibson, Chris and Deborah Davidson. 'Tamworth, Australia's "Country Music Capital": Place Marketing, Rurality, and Resident Reactions.' Journal of Rural Studies 20 (2004): 387-404.

Goodall, Heather. "'Fixing" the Past: Modernity, Tradition and Memory in Rural Australia,' UTS Review 6.1 (2000): 20-40.

Gorman-Murray, Andrew, Gordon Waitt, and Chris Gibson. 'Chilling Out in the Country? Interrogating Daylesford as a "Gay/Lesbian Rural Idyll"'. Queer Spaces: Centres And Peripheries. Conference Proceedings. Eds N. Stead and J. Prior. Sydney: University of Technology, Sydney, 2007. 
20-21 February 2007. <http://www.dab.uts.edu.au/Conferences/ Queer_Space/Proceedings/Rural_Gorman-Murray.pdf.>

'A Queer Country? A Case Study Of The Politics Of Gay/Lesbian Belonging In An Australian Country Town.' Australian Geographer 39.2 (2008): 171-191.

Halfacree, Keith. 'Locality and Social Representation: Space, Discourse and Alternative Definitions of the Rural.' Journal of Rural Studies 9.1 (1993): 23-37.

Hirst, John. 'The Pioneer Legend.' Australian Historical Studies 18 (1978): 316-37.

Horton, David. Ed. The Encyclopaedia of Aboriginal Australia: Aboriginal and Torres Strait Islander History, Society and Culture. Canberra: Aboriginal Studies Press, 1994.

Lane, Ruth and Gordon Waitt. 'Authenticity in Tourism and Native Title: Place, Time and Spatial Politics in the East Kimberley.' Social and Cultural Geography 2 (2001): 381-405.

Lawrence, Rebecca and Chris Gibson. 'Obliging Indigenous Citizens? Shared Responsibility Agreements in Australian Aboriginal Communities.' Cultural Studies 21 (2007): 650-671.

Little, Jo. 'Rural Geography: Rural Gender Identity and the Performance of Masculinity and Femininity in the Countryside.' Progress in Human Geography 26 (2002.): 665-670.

— and Patricia Austin. 'Women and the Rural Idyll.' Journal of Rural Studies 12 (1996): 101-111.

Macintyre, Stuart and Anna Clark. The History Wars. Melbourne: Melbourne UP, 2003.

Marston, Sallie. 'A Long Way From Home: Domesticating the Social Production of Scale.' Scale and Geographic Inquiry: Nature, Society And Method. Eds Eric Sheppard and Robert Mcmaster. Oxford: Blackwell, 2004. 170-191.

- 'The Social Construction of Scale.' Progress in Human Geography 24.2 (2000): 219-242.

McCarthy, James. 'Rural Geography: Globalizing the Countryside.' Progress in Human Geography 32 (2008): 129-137.

Mormont, Marc. 'Who is Rural? Or How To Be Rural: Towards a Sociology of the Rural.' Rural Restructuring: Global Processes and Their Responses. Eds Terry Marsden, Patrick Lowe, and Sarah Whatmore. London: David Fulton, 1990. 21-44.

Phillips, Martin. 'The Restructuring of Social Imaginations in Rural Geography.' Journal of Rural Studies 18 (1998): 113-122. 
—, Rob Fish, and Jennifer Agg. 'Putting Together Ruralities: Towards a Symbolic Analysis of Rurality in the British Mass Media.' Journal of Rural Studies 17 (2001): 1-27.

Pini, Barbara. 'Managerial Masculinities in the Australian Sugar Industry.' Rural Society 14.1 (2004): 22-35.

Pritchard, Bill and Phil McManus. Eds. Land of Discontent: The Dynamics of Change in Rural and Regional Australia. Sydney: UNSW Press, 2000.

Reynolds, Henry. The Other Side of the Frontier: Aboriginal Resistance to the European Invasion of Australia. Melbourne: Penguin, 1982.

Rye, Johan. 'Rural Youth's Images of the Rural.' Journal of Rural Studies 22 (2006): 409-421.

Short, Brian. 'Idyllic Ruralities.' Handbook of Rural Studies. Eds Paul Cloke, Terry Marsden, and Patrick Mooney. London: Sage, 2006. 133-148.

Staples, Max. 'Tasmania as Little England and the Social Construction of Landscape.' Rural Society 13.3 (2003): 312-329.

Valentine, Gill. Social Geographies: Space and Society. New York: Prentice Hall, 2001.

Vanderbeck, Robert and Cheryl Morse Dunkley. 'Young People's Narratives of Rural-Urban Difference.' Children's Geographies 1 (2003): 241-159.

Waitt, Gordon. 'Selling Paradise and Adventure: Representations of Landscape in the Tourist Advertising of Australia.' Australian Geographical Studies 35 (1997): 47-60.

Ward, Russel. The Australian Legend. 1958. Melbourne: Oxford UP, 1984.

Waterhouse, Richard. The Vision Splendid: A Social and Cultural History of Rural Australia. Perth: Curtin U Books, 2005.

Williams, Raymond. The Country and the City. London: Chatto \& Windus, 1973.

Woods, Michael. 'Engaging the Global Countryside: Globalization, Hybridity and the Reconstitution of Rural Place.' Progress in Human Geography 31.4 (2007): 485-507.

- Rural Geography: Processes, Responses and Experiences in Rural Restructuring, London: Sage, 2005. 